\title{
A SUBJETIVIDADE NA ENFERMAGEM - O DISCURSO DO SUJEITO NO CUIDADO
}

\author{
SUBJECTIVITY IN NURSING - THE DISCOURSE OF THE \\ SUBJECT IN CARE \\ LA SUBJETIVIDAD EN LA ENFERMERIA - EL DISCURSO DEL SUJETO \\ EN EL CUIDADO
}

Enéas Rangel Teixeira'

\begin{abstract}
RESUMO: Neste artigo, realizo uma reflexăo sobre a subjetividade do cliente no cuidado de enfermagem. Coloco em foco o discurso do sujeito como uma realidade operante no cuidado e as maneiras que ele se utiliza para cuidar de sua saúde. Para que ocorra uma interaçăo eficaz entre o enfermeiro e o cliente, é preciso saber ouvir o discurso do outro, pois aí afloram as representações, o desejo e as motivaçōes para o cuidado com o corpo. O cliente busca de modo coadjuvante, outras modalidades de cuidados que atendem sua subjetividade. Concluo que, o discurso do sujeito não é apenas um subsídio para o diagnóstico e que é importante perceber as expressōes do cliente e buscar espaços e estratégias adequadas a essa abordagem.
\end{abstract}

PALAVRAS CHAVE: subjetividade, sujeito, cuidado, enfermagem

\section{CONSIDERAÇÕES INICIAIS}

No decorrer de minhas vivências com os clientes, venho observando o surgimento de determinadas representações, que apresentam efeitos no cuidado dessas pessoas. Ao realizar visitas domiciliares, consulta de enfermagem e entrevistas nas casas dos clientes, como pesquisador e como professor de enfermagem, pude exercitar a capacidade de ouvir e perceber que as formas de cuidados que os sujeitos apresentam são diferentes daquelas norteadas pelo discurso técnico e científico.

Entendo que a palavra do sujeito expressa sua subjetividade e tem potencialidades no cuidado com o corpo, pois a decisão da eficácia do autocuidado depende das motivações conscientes ou inconscientes do sujeito. Segundo Faustino (1995, p.31), a palavra tem sentido no contexto em que ela é dita e seu uso é como instrumento que leva à ação.

Nessa perspectiva, tenho como objetivo realizar uma reflexão teórica a respeito das representações do cliente sobre o cuidado com o corpo, a partir do contexto sociocultural e da subjetividade do sujeito. Assim, restrinjo-me ao discurso do sujeito da classe popular, tendo em vista que trabalhamos, na maioria das vezes, com essa clientela nas instituições públicas.

O discurso do cliente sinaliza a dimensão subjetiva que norteia o cuidado com o corpo, demonstrando pluralidades de recursos que o sujeito utiliza para seu autocuidado, que vão desde as representaçōes técnicas e científicas às representaçōes mágicas e religiosas (Teixeira, 1998).

Neste contexto, subjetividade é entendida como produção de sentido, com potencialidade de criação e não meramente como algo vago relacionado à introspecção individual. Subjetividade

'Professor do Departamento de Enfermagem Médico-cirúrgica da Escola de Enfermagem da UFF e da UERJ. Coordenador do Núcleo de Estudos e Pesquisas em Subjetividade na Enfermagem (EEUFF). Doutor em Enfermagem. 
não é uma essência, pois está implicada na produção continua de novas virtualidades, ou num processo de criação contínua através das singularidades. Nessa perspectiva tanto o sujeito quanto o objeto são produzidos e não existe subjetividade mas subjetividades. Entretanto, a produção capitalista gera um tipo de subjetividade, homogeneizadora das diferenças, que permeia o social, o individual e a ecologia humana. Segundo Guattarie Rolnik (1986), não existe uma subjetividade geral, mas subjetividades, e muitas são produzidas pelo capitalismo moderno, via mídia e outros agentes de ressonância.

\section{O DISCURSO SOBRE SAÚDE, DOENÇA E CUIDADO COM O CORPO}

O sujeito da classe popular utiliza recursos que expressam a sua linguagem corporal, de modo que suas representações estão relacionadas às habilidades físicas do seu cotidiano. Isto indica uma forma de vida, na qual a saúde é considerada como felicidade, alegria e força para o trabalho, divergindo de uma concepção centrada na doença ou na sua ausência.

Boltanski (1979) fala que o sujeito da classe popular apropria-se de determinadas categorias do discurso técnico-científico e as reinterpreta de acordo com seu contexto cultural.

Duarte (1986), também, ressalta que houve uma difusão e apropriação do saber médico pelo saber popular, o qual produz reinterpretação do discurso técnico. Entretanto, quando se compara o discurso popular com o científico, o primeiro é considerado, por uma visão elitista, como fracionado e insipiente. Todavia, se esse discurso for bem analisado, apresenta uma coerência interna, como demonstra Boltanski $(1979$, p.23), quando fala da representação da doença, pois essas representações "são às vezes relativamente bem acabadas, coerentes e explicitas".

Nessa forma de pensar, Costa $(1989$, p.20) afirma que o discurso popular, por ser considerado fracionado, não significa que seja inferior, pois o seu entendimento não implica uma hierarquia de valor. Quando o pensamento popular é percebido, de uma maneira compreensiva e contextualizada, pode ser totalizante e expressar, de modo mais nítido, a realidade do sujeito. O pensamento popular tem uma cosmovisão da saúde e da doença, diferente da ciência oficial, pois é fruto das estratégias de sobrevivência, enquanto condição de classe social do sujeito no cuidado do seu corpo. Portanto, essas representações geram um tipo peculiar de subjetividade que relaciona o sujeito em seu contexto sociocultural.

A representação popular da doença permite que o cliente construa um sentido para a vida e "possibilita ao sujeito naturalizar a estranheza do mal que o acomete" (Costa,1989, p.20). Nessa perspectiva, existem várias explicações para o surgimento da doença, que vão desde uma visão biomédica à perspectiva mágica e religiosa. A doença é representada por situações relacionadas às habilidades e às experiências do cotidiano.

A representação que o sujeito da classe popular apresenta sobre a doença não é igual à descrição nosográfica das doenças, pois o mesmo não possui equipamentos lingüísticos para descrever suas sensações corporais, por meio dessas representações eruditas. Entretanto, 0 sujeito da classe popular apropria-se de determinados termos médicos e o readapta a sua subjetividade. Assim, as representações demonstram uma coerência de acordo com a visão de mundo dos sujeitos. Nessa forma de pensar, a saúde é entendida como força para realizar as atividades diárias e a doença é percebida como fraqueza, algo negativo que vem impedir a realização das atividades diárias.

Nesse contexto, o emprego do termo nervoso indica uma categoria para expressar conflitos psicológicos, pois o sujeito da classe popular não possui um discurso erudito para nomear suas sensações. Desse modo, o nervoso não se refere ao orgânico, mas aos aspectos psicológicos gerados por tensões das contradições sociais, que são vividas pelo sujeito. A doença dos nervos é utilizada para revelar problemas da ordem psíquica e afetiva e não ao sistema nervoso em si, como fala Costa (1987). 
O saber popular classifica as doenças como malignas e benignas. Assim, são consideradas doenças malignas: o câncer, a tuberculose, a lepra e a AIDS e benignas as que não levam à morte de imediato, não são contagiosas e nem produzem deformidades, como exemplo, o diabetes e a hipertensão. A força dessas representações sociais evidencia-se quando o profissional de saúde apresenta certas precauções em revelar certos diagnósticos ao sujeito. Isto ocorre, porque, em nossa cultura, cada doença tem uma representação, cercada de mitos e metáforas, que precisam ser melhor trabalhadas em nossa prática quotidiana (Teixeira, 1994; Tavares e Teixeira,1998).

Nessa perspectiva, as particularidades culturais do cotidiano, que determinam formas de subjetivação, são funcionais na vida do sujeito. As representações coletivas oriundas dos discursos dos sujeitos falam da pluralidade do cuidado com o corpo, das sensações corporais e da estética. Essas representações são eficazes, pois elas não são apenas ideários, mas úteis na vida do sujeito. As representações abarcam os aspectos cognitivos, sociais e afetivos. Em razão disso, não existe uma concepção única e universal sobre a doença, pois a sua consciência "extrapola a consciência do desequilíbrio bio-psíquico para desdobrar-se na consciência do estatuto social ocupado pelo sujeito na sociedade" (Costa,1987, p.7).

A relação com o cliente envolve jogos de linguagem e entra, nesse conjunto, a multiplicidade das representações sociais. Forma-se, então, um campo de tensão entre um saber de cunho técnico e científico, prescritivo, que tem como com objetivo produzir mudanças nos hábitos dos sujeitos e, por outro lado, as representações dos clientes que expressam suas vivências corporais. No entanto, esse processo não se sustenta por uma relação vertical, pois o sujeito desejante dribla, muitas vezes, esse saber instrumental. O cliente, inicialmente, pode criar dependência em relação às prescrições dos profissionais de saúde para se cuidar, entretanto, à medida que vamos nos aprofundando na sua singularidade, percebemos que ele reinterpreta o saber técnico-cientifico, busca outras formas de cuidado ou resiste ao tratamento oficial.

Então, é vital um deslocamento daquela visão do cliente pouco reativo, pronto a colaborar com nossas intervenções instrumentais, para percebê-lo como cidadão, possuidor de direitos sociais. Considero que é através do exercício da cidadania que o indivíduo torna-se sujeito e representa a sociedade que está inserido.

A Enfermagem mantém uma contínua convivência com os clientes, de modo que isso Ihe possibilita grandes oportunidades de interação. Entretanto, nossa capacidade de ouvir ainda é limitada, pois desenvolvemos mais a visão e as habilidades manuais e nos condicionamos às rotinas da instituição. A habilidade de ouvir e de se aproximar do cliente favorece a relação terapêutica e abre espaço para a dimensão sensível do cuidado. Para isso, é relevante saber aproximar-se do cliente e ter sensibilidade em perceber, no outro, os aspectos verbais e as expressões corporais; aspectos que nos instigam, também, a procurar nosso autoconhecimento.

Os enfermeiros se vêem implicados com as representações dos sujeitos que entram em cena na relação cuidadora. Em relação a isso, uma postura ética torna-se desejável, no sentido de respeitar as divergências, as crenças e os hábitos dos clientes. As representações heterogêneas no cuidado são singulares e produzem agenciamento ${ }^{2}$ coletivos, no sentido de levar à criação de espaços de vivências e maior participação do usuários no campo da saúde.

O cuidado com o corpo é uma pluralidade, no qual transitam representações, que não se pulverizam frente ao saber alopático hegemônico. Isto se processa porque o sujeito da classe

\footnotetext{
${ }^{2}$ Agenciamento é um conceito colocado por Guattari e Rolnik (1986, p.317), que se opõe a noção de estrutura, sistema e forma. Por meio do agenciamento coletivo, o desejo se expressa e se operacionaliza no real, produzindo transformações. Por exemplo, o desejo de mudança social se concretiza quando grupos ou sujeitos se aliam para conquistar seus direitos. $O$ agenciamento é heterogêneo, comporta elementos psíquicos, sociais, ecológicos e imaginários. Ele se opõe ao complexo freudiano que se restringe ao inconsciente individual.
} 
popular revela uma variedade de representaçōes que falam de seus recursos materiais e afetivos em relação às vicissitudes da vida. O cotidiano demonstra que o modo como o sujeito cuida de sua saúde não é universal, pois ele expressa as condições de vida e as estratégias de que dispőe para manter seu bem estar. Emerge, portanto, uma pluralidade de representações, que vão desde a reinterpretaçăo do saber científico até às práticas populares de saúde. $O$ discurso do sujeito coloca situaçōes que denunciam as condições do meio ambiente, a violência e o desamparo que o cidadão tem em nossa sociedade.

\section{A DIMENSÄO SUBJETIVA NO CUIDADO EM ENFERMAGEM}

O esteio de abordagem do cliente na enfermagem, comumente, baseia-se no atendimento das necessidades humanas básicas. Essa base conceitual concede um caráter instrumental e funcional às ações do enfermeiro. Porém, se percebermos, nas entrelinhas, existem outros aspectos da vida do cliente que não estamos acostumados a trabalhar, por exemplo: quando o sujeito expressa seu desejo de vida; as prática populares em saúde; as atividades lúdicas; a dimensäo inconsciente dos hábitos de vida; os aspectos psicossomáticos; as resistências ao tratamento; os quais podem contrariar as ações instrumentais do técnico da saúde. Portanto, ao lado do funcional, emerge o estético, que abarca a sensibilidade, que nos desafia a buscar novas perspectivas de cuidar. $O$ estudo da subjetividade é um caminho para a compreensão do estético e do expressivo no cuidado.

Nessa perspectiva, as pessoas podem ter vontade contrária à boa saúde, mesmo tendo explicações racionais sobre as práticas saudáveis do bem viver. Assim, exemplifico: o tabagismo; a compulsão pelo doce no diabético; a vontade que tem o hipertenso em rejeitar comidas insossas; a grande incidência de doenças mentais nos profissionais de saúde; entre outros exemplos. Tal paradoxo aponta a existência de outra ordem que é a dimensão inconsciente do desejo, que não acompanha necessariamente a lógica da necessidade. Pela perspectiva do sujeito desejante, o que se chama de saudável, pode parecer sem graça.

As atitudes contrárias dos clientes parece que vêm subverter as orientações normativas, pois podem ser uma reação do desejo do sujeito frente ao fardo do instituido. A experiência mostra que a vida é tortuosa, foge muitas vezes dessas regras pré estabelecidas. $O$ que se chama de normal se refere às categorias universais introjetadas e, nesse sentido, todas aquelas sensações que ameaçam essas categorias, têm equivalência de anormalidade, sendo caracterizadas como desvio (Costa,1989).

Nessa visão, o cuidado de enfermagem não está restrito necessariamente ao corpo, como na medicina dos órgãos, mas ao sujeito que vivencia a saúde, a doença e seu próprio cuidado. Mesmo nos lugares, como: centro de terapia intensiva; centro cirúrgico; emergência, necessitam trabalhar com a dimensão subjetiva do cliente no cuidado. Nesses espaços, os atores da saúde tendem a remover: os simbolos da cultura ( roupas, anéis, relógios, cordöes, noção do tempo, entre outros ) e a própria linguagem; a consciência é restrita pela sedação e anestesia. Trabalhar com a subjetividade, nos coloca numa situação que vai além do aspecto instrumental de nossa prática.

Assim, quando falamos do cuidado, pensamos na higiene, na nutrição, na mobilização do corpo, na mudança de hábito do sujeito, nas eliminaçōes, nos curativos, entre outros. Entretanto, o cliente tem suas representações, que o marcam como ser desejante, que se expressa pela linguagem, a qual cria uma outra configuração de cuidado, que relativiza o enfoque tecnicista e organicista.

Considero que não basta apenas adquirir o conhecimento técnico e científico para viver "saudável", pois, se assim fosse, os profissionais de saúde seriam mais saudáveis do que os demais sujeitos, o que não é uma verdade. Torna-se emergente, o conhecimento das emoções, de modo que o sujeito entre em contato com seus sentimentos, com seu corpo e com o próprio 
processo de cura. Isto é viável, no espaço, em que a subjetividade se expressa por meio da linguagem, tais como: dinâmica de grupo, nas atividades artisticas na saúde, na participação do usuário na instituição, na relação terapêutica, entre outros.

Contudo, o discurso cientificista ignora a dimensão subjetiva ou utiliza-se dela para impor seu poder pela racionalização. Assim, inserem-se muitos profissionais de saúde que consideram o discurso popular como inferior ou primitivo. Entretanto, o cliente comumente utiliza o discurso da doença para chegar ao profissional, para poder falar dos problemas afetivos, pois se usasse o discurso referente aos seus reais sentimentos não seria atendido. Assim, o discurso da doença funciona como um álibi para o sujeito falar de si e de suas tensão.

O relacionamento que se processa no campo clínico, não é um relacionamento comum entre duas pessoas, mas uma relação profissional - que traz consigo toda uma carga teórica conceitual-epistemológica, construida no espaço da clínica, que norteia os atos do profissionais e prevê as possíveis reações do cliente (Foucault,1994). O cliente, nesse sentido, é uma construção teórica sob o olhar do paradigma realista - positivista. Todavia, quando emergem aspectos subjetivos que desafiam essa construção epistemológica, tenta-se classificá-los, ignoráIos ou eliminá-los. A dimensão subjetiva abarca as emoções, o desejo, a intuição, a sexualidade, entre outros, numa dimensão dionisiaca do ser que a Pós-Modernidade traz novamente à tona.

\section{CONSIDERAÇÖES FINAIS}

O saber popular não é inferior e não é superado pelo conhecimento técnico-científico, pois esse saber popular atende a dimensão subjetiva do sujeito em relação à vida e ao cuidado com o corpo. Se estamos impondo formas de cuidados ditas universais sobre as formas de cuidado do cliente, estamos realizando uma violência simbólica, sobre o corpo e a habilidade do outro, impossibilitando um genuína relação cuidadora.

Para entender o discurso popular, é preciso entender sua utilidade ao invés de reter-se exclusivamente no seu significado, que, muitas vezes, usa uma roupagem de organicidade ("nervoso", "problema de cabeça", "o sangue que sobe") para expressar a subjetividade. Desse modo, as categorias da linguagem popular, no que se refere à mente e ao corpo, diferenciamse das categorias científicas e expressam a existência de um mundo cultural do sujeito, que atende seus aspectos subjetivos de existência.

A reflexão e libertação ocorrem à medida que compreendemos o mundo das representações sociais dos sujeitos e a sua força no cuidado com o corpo. A racionalidade científica moderna rejeitou as práticas populares, a intuição e a sensibilidade, ou seja, o registro estético nas práticas de cuidado. Contudo, sentimos, hoje, que esses aspectos emergem em potencialidade, conduzindo à maior expressividade em nossas reflexöes e ações.

No campo da saúde, existem duas formas discursivas sobre o corpo do sujeito: a representação biomédica, técnica, científica e dessubjetivada; a representação do sujeito ligada à sua história de vida, aos seus sentimentos e à sua subjetividade. Nesse lugar, entre a objetividade e a subjetividade, nos situamos para cuidar do sujeito, ou seja, entre o estético e o funcional. É bom destacar que o cuidado apresentado pelo senso comum não se descola da estética e da sensibilidade, enquanto que o discurso técnico científico, que norteia as práticas em saúde, desloca-se.

É conveniente que o enfermeiro entenda a dimensão subjetiva, não tentando rotular as manifestações discursivas com um diagnóstico fechado, pois, muitas vezes, a expressão do cliente pode revelar situações que vão além do significado corriqueiro da palavra.

Assim, as estratégias de cuidado com o corpo vão se dar de acordo com o contexto em que o sujeito está inserido. É no corpo e nas suas habilidades, que as palavras tomam forma, moldando-se e fazendo moldar os outros. Nesse sentido, compactuamos com as seguintes palavras de Rodrigues (1979, p.130): "No corpo, a ordem fisiológica material se une à ordem 
ideológica, moral, como signos, nos quais se encontram e se reúnem, o sensível e o inteligível, o significante e o significado."

Torna-se emergente criar espaços para trabalhar com a subjetividade no cuidado de enfermagem e entender que a subjetividade não é apenas um subsidio para o diagnóstico.

ABSTRACT: This reflects on the importance of the client's subjectivity in the nursing care process. It focuses on the client's discourse as an effective component in the care and the resources he utilizes to care for his/her health. In order to have an efficient interaction between nurse and client, it is necessary to know how to listen to the discourse of the other, for it is there that surface representations, desire and motivation for the care of the body. The client seeks concurrently other forms of care that satisfy his/her subjectivity. I conclude that the client's discourse represents not only an essential contribution to the diagnosis, but that it is also important to perceive the client's expressions and to seek appropriate strategies.

KEYWORDS: subjectivity, client, care, nursing

RESUMEN: En este artículo hago una reflexión sobre la subjetividad del cliente en el cuidado de enfermeria. Focalizo el discurso del sujeto como una realidad operante en el cuidado y las formas que él utiliza para cuidar de su salud. Para que ocurra una interacción eficaz entre el enfermero y el cliente, hace falta saber oir el discurso del otro, pues ahi afloran las representaciones, el deseo y las motivaciones para el cuidado con el cuerpo. El usuario busca, de modo coadyuvante otras modalidades de cuidados que atienden a su subjetividad. Concluyo que el discurso del sujeto no es tan sólo un subsidio para el diagnóstico y que es importante percibir las expresiones del cliente y buscar espacios y estrategias adecuados a ese tipo de enfoque.

PALABRAS CLAVE: subjetividad, sujeto, cuidado, enfermeria

\section{REFERÊNCIAS BIBLIOGRÁFICAS}

BOLTANSKI, Luc. As classes Sociais e o corpo. Rio de Janeiro:Graal, 1979.

COSTA, Jurandir Freire. A consciência da doença, enquanto consciência do sintoma: a doença dos nervos e a identidade psicológica. Cadernos do Instituto de Medicina Social. Rio de Janeiro:IMS/ UERJ, v. 1, n. 1, p. 4-45, mar./abr. 1987.

Psicanálise e contexto cultural. Imaginário psicanalitico, grupos e psicoterapia. Rio de Janeiro:Campus, 1989.

DUARTE, Luis Fernando. Da vida nervosa nas classes trabalhadoras urbanas. 2. ed. Rio de Janeiro:Zahar, 1986.

FAUSTINO, Silvia. Wittgenstein - O eu e sua gramática. Săo Paulo:Ática, 1995. 
FOUCAULT, M. O nascimento da clínica, 4. ed. Rio de Janeiro: Forense Universitária, 1994.

GUATTARI, Félix; ROLNIK, Suely. Micropolitica Cartografias do Desejo. Rio de Janeiro:Vozes, 1986.

RODRIGUES, José Carlos. Tabu do corpo. 3. ed. Rio de Janeiro:Achiemé, 1979.

TAVARES, Cláudia Mara de Melo; TEIXEIRA, Enéas Rangel. Trabalhando com as representações sociais na enfermagem. In: GUATHIER, Jacques Henri Maurice et al. Pesquisa em Enfermagem Novas Metodologias Aplicadas. Rio de Janeiro: Guanabara Koogan S. A, 1998

TEIXEIRA, Enéas Rangel. O desejo e a necessidade no cuidado com o corpo - uma perspectiva estética na prática de enfermagem. Rio de Janeiro, 1998. Tese (Doutorado em Enfermagem) Escola de Enfermagem Anna Nery - UFRJ.

O mel que passa: representaçōes sobre saủde, doença e o autocuidado. Rio de Janeiro, 1994. Dissertaçāo (Mestrado em enfermagem) - Escola de Enfermagem Anna Nery - UFRJ 